\title{
La represión política en Rio Negro en las décadas de 1930 y 1940. El caso de los anarquistas ${ }^{1}$
}

\author{
Graciela Noelia Suárez
}

Universidad Nacional del Comahue

A fines del siglo XIX en la Argentina, la llegada de numerosos contingentes de inmigrantes proporcionó mano de obra a un país de escasa población y extensión dilatada. A la par, emergió y se desarrolló el movimiento obrero con el consiguiente surgimiento de conflictos que se tradujeron en huelgas, manifestaciones, boicots, atentados. La aparición de los gremios, los movimientos anarquistas y el socialismo a comienzos del siglo XX, alarmó a la elite gobernante y "forzó una respuesta del Estado no siempre acorde con los fundamentos liberales que guiaban su acción en otras áreas" (Zimmermann, 1995: 133). Estas respuestas se tradujeron en la sanción de leyes punitivas, como la de Residencia (1902) y Defensa Social (1910) además del perfeccionamiento y la especialización de la Policía de la Capital Federal (creación del Escuadrón de Seguridad en 1893, destinado al control y represión de manifestaciones públicas realizadas en la ciudad de Buenos Aires, y de la Sección Especial, en 1901) con la misión de controlar las actividades de anarquistas y socialistas. A ello se le suma la incorporación de instrumentos facilitadores del relevamiento de la población "sospechada", como la instauración del sistema dactiloscópico (1904), el prontuario y la Cédula de Identidad (1907).

Durante los gobiernos radicales se produjeron, con un gran protagonismo del movimiento obrero y un rol destacado del anarquismo, hechos de gran conflictividad social como la Semana Trágica (Buenos Aires, 1919), las huelgas de la Patagonia (Santa Cruz, 1920-1921) y los

\footnotetext{
1. El presente trabajo fue realizado en el marco del "Proyecto Estado y Territorios Nacionales. Poder y ciudadanía en Río Negro. 1930-1955”. Una versión preliminar de este trabajo se presentó en las Jornadas de Investigación y Extensión del Centro Universitario Zona Atlántica, Universidad Nacional del Comahue, Viedma, 8, 9 y 10 de setiembre de 2010 .
} 
sucesos de Jacinto Arauz (La Pampa, 1921), dominados con la consecuente brutal represión.

Durante estos años, las organizaciones gremiales, el anarquismo y el socialismo "fueron rápidamente catalogados por el imaginario de las clases dominantes como deformaciones externas, ajenas al cuerpo social de la Nación, y por lo tanto, extirpables" (Flier, 2006: 2). Es así que, a partir de la vinculación del extranjero, el delincuente y el anarquista, se construye la imagen del enemigo interno, el otro. El anarquista es quien ocupará la otredad, y sobre él, mayormente, recayeron las acciones represivas y las leyes de exclusión.

En tanto, el quiebre del orden institucional en 1930, además de la limitación de los derechos civiles y supresión de los políticos para toda la población, significó para las organizaciones obreras y particularmente para anarquistas y comunistas una dura etapa signada por detenciones, deportaciones y fusilamientos. El objetivo de esta investigación es estudiar los alcances que tuvo en Río Negro durante la décadas de 1930 y 1940, esta persecución orientada a castigar acciones político-sociales. Para ello nos centramos en la represión llevada a cabo, en 1931, contra un grupo de anarquistas, quienes fueron los primeros en padecerla durante el transcurso de esos años, según las fuentes relevadas.

En la investigación se procura una caracterización de los detenidos a partir de establecer cuántos y quiénes eran y su lugar de residencia, tratando de delinear trayectorias de vida de algunos de ellos. Además, se intenta, a partir del examen de las fuentes policiales (informes, interrogatorios, sumarios), por un lado, descubrir evidencias que orienten a afirmar que los arrestados acusados de ácratas - por su nacionalidad, ocupación, antecedentes laborales, políticos y gremiales- participaban de la imagen del enemigo interno construida por las elites gobernantes, exacerbada en ese contexto dictatorial. Por otro lado, indagar a través de los procedimientos aplicados en las detenciones y de los registros policiales, el grado de perfeccionamiento y especialización que tenía la policía territoriana para cumplir con las tareas de represión política.

La exploración documental -fundamentalmente la originada por el Poder Ejecutivo rionegrino: gobernador y jefe de policía- no suministró información sobre esta acción represiva: no encontramos ni órdenes, ni listado, ni informes. No decimos que no existieron, sino que no están en el Archivo Histórico de la Provincia de Río Negro. ${ }^{2}$ Tampoco fue muy abundante la información registrada en los periódicos locales La Nueva Era y el Río Negro. Pero son los Prontuarios policiales -correspondientes a la Sección Orden Social (OS) de la Jefatura de Policía-, iniciados

2. Esta constatación se basa en la documentación existente en el Archivo Histórico de la Provincia de Río Negro (en adelante AHPRN) en su sección Prontuarios. 
en Río Negro en 1931, los que posibilitaron reconstruir en parte este accionar represivo.

La investigación se centra en Río Negro -norte de la región Patagónica-, que en el periodo estudiado estaba organizado como territorio nacional, entidad político-administrativa que a diferencia de la provincia ${ }^{3}$ carecía de autonomía, pues tanto su organización política como administrativa y la asignación de fondos presupuestarios era responsabilidad del Estado nacional, en tanto sus habitantes tenían los derechos políticos limitados a los comicios municipales y estaban privados de participar en la elección de las autoridades nacionales y territoriales.

En cuanto a la relación entre el Estado nacional y los gobernadores territoriales, Martha Ruffini, basándose en las notas cursadas desde el gobierno central durante los primeros años de organización de estas jurisdicciones, destaca cómo se evidencia el control de los gobernadores reforzando el centralismo, así el "Estado, con tono discursivo admonitorio, ordenaba el cumplimiento de las normas sin excusas ni dilaciones" (2007: 172). La dependencia de los territorios del Ejecutivo nacional se concretaba a través del Ministerio del Interior, transformando a los gobernadores en delegados con grandes limitaciones para el desarrollo de sus funciones, situación que se profundizó con el golpe militar.

\section{El anarquismo argentino en las décadas del 30 y 40}

A principios del siglo $\mathrm{XX}$, los anarquistas "habian logrado cierto éxito en el mundo del trabajo", afirma Juan Suriano, en tanto controlaban la FORA, la principal organización sindical; además su prédica se difundía por una importante cantidad de círculos culturales y periódicos, y la demostración de su poder de movilización se visibilizaba en manifestaciones de protesta y conmemoraciones del 1 de mayo. Para comprender la adhesión que habían alcanzado hay que tener en cuenta las condiciones de explotación, pobreza y marginalidad a las que estaban sometidos los trabajadores, quienes mayoritariamente provenían de la inmigración (2000: 294).

La agudización de los conflictos obreros recibió como respuesta la represión del gobierno, especialmente durante la celebración del Centenario. "La nueva Ley de Defensa Social y la aplicación del estado de sitio brindaron el marco legal para amordazar a la prensa, cerrar locales, así como encarcelar y deportar activistas", lesionando sobre todo al

3. Con la incorporación de la Patagonia y el noreste argentino -tierras obtenidas luego de las compañas militares contra los indígenas- y a partir de la ley 1532 del año 1884, el Estado nacional quedó conformado por catorce provincias y nueve unidades político-administrativas, que recibieron la denominación de Territorios Nacionales. 
anarquismo en su actividad gremial. Con la deportación o el destierro a Tierra del Fuego fueron castigados decenas de dirigentes extranjeros y nativos. Si bien dos años más tarde la situación se normalizó, el anarquismo no pudo recuperar su influencia en el movimiento obrero (Suriano, 2000: 306-307).

Con respecto a la tesis del debilitamiento de la acción anarquista a partir de la primera década del siglo XX y su desaparición en los 30, es discutida por nuevos trabajos aparecidos en los últimos años. Para Nicolás Iñigo Carrera los estudios anteriores solo tomaban "en consideración a la FORA, dejando de lado el proceso de reagrupamiento que se estaba produciendo con la formación de los comités de relaciones anarquistas y posteriormente con la Federación Anarco Comunista Argentina (FACA) y la Alianza Obrera Spartacus" (2009: 8-9). En la misma orientación, Agustín Nieto sostiene que "al igual que socialistas y comunistas, los anarquistas estaban desarrollando fructíferas experiencias en el mundo del trabajo durante las décadas del 30 y 40" (2010: 247). Este vacío en los estudios sobre el accionar anarquista se explica porque la historiografia argentina se ha focalizado en las "fuerzas que operaban dentro del sistema electoral, o dentro de otro espacio cuyo peso en el aparato productivo (y por lo tanto en la esfera política) era visible: el movimiento obrero" (Pérez, Heredia y Villasenin, 2005: 109). Afirmación que coincide con la perspectiva de Iñigo Carrera, cuando expresa que se estudió solamente lo que sucedia "dentro del sistema institucional político y jurídico donde las organizaciones anarquistas rechazaban insertarse" (2000: 2 ).

No obstante estas divergencias, hay coincidencias entre los estudiosos del anarquismo cuando se asegura que el levantamiento militar del 6 de setiembre y la toma del poder por José Félix Uriburu y significó para el movimiento uno de los momentos de mayor represión, que se inició a los pocos dias de concretarse el golpe, con la clausura de los lugares partidarios, la prohibición de sus publicaciones, la detención de los dirigentes en Devoto, Martín García y Ushuaia, la persecución de sus simpatizantes y militantes por todo el país (Pérez, 2002: 10-11).

En 1930, en Rosario, es fusilado Joaquín Penina, acusado de ser el autor de un volante contra el gobierno. En el mismo año, los choferes anarquistas José Santos Ares, José Montero y Florindo Gayoso, apresados por un conflicto en la General Motors, fueron condenados a muerte "acusados de atentado, incendio, asaltos y tiroteos con la policia; pero la movilización en contra de la medida, que incluyó gestiones de la CGT y de la colonia española, logró que se les permutara esa pena por la de cadena perpetua" (Iñigo Carrera, 2000: 7). En ese marco se producen los fusilamientos de los anarquistas Severino Di Giovanni y Paulino Scarfó, el 1 y 3 de febrero de 1931, respectivamente. 
Al levantarse el estado de sitio durante el gobierno de Agustín P. Justo, se liberaron los presos politicos y los militantes reiniciaron las actividades, constituyendo los dos grupos anarquistas más importantes de la década del 30: la Alianza Obrera Spartacus (AOS) y la Federación Anarco Comunista Argentina (FACA). "La situación de clandestinidad y la clausura de los locales politicos implicaban nuevas prácticas y, entre ellas, trasladar la atención al lugar de producción", tal es así que estas agrupaciones impulsaron la organización de los obreros en su lugar de trabajo; de allí "la intención manifiesta de poseer una política específica de militancia en las fábricas, empresas y talleres” (Ceruso, 2011: 234, 240, 254).

La FACA, surgida en 1935 -un año antes lo habia hecho la AOS-, además de su trabajo sindical, a través de sus publicaciones brindó un amplio apoyo a los republicanos españoles durante la guerra civil. Además, contó con el periódico Acción Libertaria (Iñigo Carrera, 2000: 10) y sus actividades atraviesan toda la década de 1940 hasta su designación como Federación Libertaria Argentina en 1955 (Pérez, Heredia y Villasenin, 2005: 110-111). En tanto, la disolución de Spartacus (la publicación que editaron con ese nombre se ha perdido) no es conocida con exactitud (Iñigo Carrera, 2000: 12); Javier Benyo la sitúa aproximadamente en los primero meses de 1940 (2005: 177).

Las actividades de militancia y el trabajo gremial fueron duramente reprimidos durante las décadas del 30 y 40, las principales armas utilizadas por el gobierno para desarticular la protesta social se concretaron a través de la expulsión del país con la aplicación de la ley de residencia y del encarcelamiento bajo la acusación de asociación ilícita.

\section{El anarquismo: la representación del enemigo}

Las reacciones del gobierno ante el accionar del movimiento obrero y del anarquismo en particular deben enmarcarse, según Eduardo Zimmermann (1995), en dos rasgos ideológicos que se consolidan a principios del siglo XX. Uno de ellos es la valoración del concepto de orden público, considerado la base del progreso económico y la garantía del funcionamiento eficiente del sistema político. En tanto, el concepto de defensa social -el otro rasgo- surgido de la corriente criminológica influida por las ideas de Rafael Garófalo y Enrico Ferri, propugna que "la sociedad tiene derecho a defenderse del sujeto delincuente, quien, por su parte, tiene el derecho a recuperarse, a ser curado, tutelado hasta que cese su peligrosidad" (Elbert, 1998: 72). La sociedad no castigaba al delincuente porque lo consideraba moralmente responsable, sino que buscaba "defenderse de ciertos individuos peligrosos", fundamentación que reemplaza "los conceptos de responsabilidad individual de la escue- 
la clásica por la idea de 'defensa social' como justificativo de la pena" (Zimmermann, 1995: 136). En sus fundamentos "se apela a una "contingencia' amenazante para limitar los derechos individuales sugiriendo que la libertad es un bien, pero debe ser regulado y controlado por el Estado". Por lo tanto si la defensa social es el fin del sistema penal "se justifica y legitiman los medios o procedimientos que sean necesarios para ello" (Pegoraro, 2003: 12-14).

A los anarquistas, a diferencia de los socialistas -aceptados por la elite política como interlocutores-, se los asoció a ciertas características sociológicas, psicológicas y biológicas. El acento se colocaba en su accionar: "individuos psicológicamente 'inadaptados' por razones genéticas o ambientales", es decir que se los consideraba portadores de "una 'patología' vinculada a la criminalidad" (Martínez Mazzola, 2003: 105-106).

El anarquista, personificado en el inmigrante, concentrado en las grandes ciudades, participante en huelgas y desórdenes, transforma la figura del extranjero "en el elemento constituyente de la nueva enfermedad social: el movimiento obrero. Enfermedad social que atenta contra el pretendido 'sentimiento nacional". De alli la aprobación de las Leyes de Residencia y Defensa Social, que excluyen al inmigrante extranjero, condenándolo al destierro (Ferrás, 2003: 141-142).

\section{La región del Alto Valle de Río Negro: su contexto económico-social en la década del 30}

El Territorio de Río Negro, a mediados del siglo XX, presentaba sus características iniciales de una jurisdicción extensa con población escasa y dispersa, grandes diferencias en el desarrollo regional, en cuanto a explotación de recursos y producción.

Dentro de las regiones rionegrinas, se destaca la denominada Alto Valle, que aquí nos interesa describir por ser el lugar de procedencia de la mayoría de los detenidos en 1931. Situada en el Valle Superior del río Negro, desplegada desde las nacientes del río en la confluencia del Limay y el Neuquén hasta su angostura en Chichinales, bordeando sus riberas habian surgido una serie de pueblos y ciudades interconectadas por caminos y ferrocarril. Entre los años 1880 y 1930 desarrolló una economía asentada predominantemente en el cultivo de la alfalfa (coexistian con una importancia menor la vid, frutales y hortalizas), expansión vinculada a las obras de regadío y a la sistematización de la tierra. A partir de los años 30, comienza a extenderse con fuerza la fruticultura, transformándose en la producción dominante, destinada sobre todo al mercado externo, comercialización que obligó a la instalación de numerosos galpones de empaque, además de bodegas, fábricas 
de conservas, molinos harineros (Vapnarsky, 1983; Iuorno, Miralles y Nasser, 2007).

En esta región, por los requerimientos económicos, la distribución de la tierra se caracterizó -en un primer momento- por el dominio de la mediana y gran propiedad, pero el proceso posterior de subdivisión de los predios dio lugar a la aparición del pequeño colono. Esta estructura productiva se sostenía en el trabajo familiar pero también en la mano de obra asalariada. Si bien el pequeño productor se constituyó en el actor socio-económico preponderante, en este escenario social también se desenvolvían los comerciantes -tanto el mayorista dueño de empacadoras como el minorista proveedor de mercancias e implementos-, los empleados y obreros de oficios variados. Además, en los tiempos de cosecha y empaque de la producción, el requerimiento de fuerza de trabajo, que no había en la zona, originaba un importante movimiento de trabajadores golondrina provenientes de las más diversas regiones del país, contratados en las chacras y empacadoras, originando en esas épocas una importante concentración de trabajadores (Vapnarsky, 1983; Iuorno, Miralles y Nasser, 2007).

En este contexto socioeconómico se concibe el panorama político gremial que describen Jorge Etchenique y Hernán Scandizzo -en un estudio sobre el anarquismo en el Alto Valle-, cuando mencionan la presencia en 1921 de dos sociedades de Oficios Varios, una en Allen y otra en General Roca, que al año siguiente se suma otra en Cipolletti juntamente con la Sección Allen de la Federación Obrera Regional Portuaria y Anexos, mientras en 1927 se conforma -en Roca- la Sociedad de Resistencia de Obreros Ladrilleros y Albañiles y Anexos, todas ellas de cuño anarquista. Estos sindicatos participaron -en febrero de 1922- del "congreso constituyente de la Federación Obrera Provincial de Buenos Aires (FOPBA) -adherida a la FORA-, realizado en la ciudad de Avellaneda. Alli se aceptó provisoriamente que las sociedades obreras rionegrinas integraran la FOPBA" (2001: 2).

La división del movimiento anarquista en el orden nacional -a comienzos de la década del 20- entre antorchistas (congregados alrededor del semanario La Antorcha) y los protestistas o foristas (agrupados en torno al diario La Protesta y a la FORA) se reproduce en Río Negro. Hacia 1925, junto a los foristas, concentrados en el Centro Obrero, como era conocido el local de Oficios Varios de Roca, también tienen una presencia importante los antorchistas, quienes desarrollaban sus actividades en la Agrupación Anarquista Progreso y Cultura de esa localidad, año en que apareció el primer número de su periódico Progreso y Cultura (Etchenique y Scandizzo, 2001: 2-3).

Alrededor de 1923, la presencia de simpatizantes e incluso activistas libertarios en la zona es posible registrarla a través de un sumario po- 
licial, sustanciado con motivo de hechos delictivos contra comercios de Allen y Plottier. En el expediente judicial aparecen declaraciones de los acusados, como éstas: "Que la lectura de libros de ideas avanzadas no han sido las causantes de que cometiera el delito sino por causa de la miseria y el hambre" (Andrés Gómez, español, 23 años, jornalero), "soy un hombre trabajador dado a la profesía [sic] de ideas anarquistas y libertarias del proletariado" (Esteban Hernando, español, 29 años, peón rural), mientras a otro de los involucrados se lo registra como afiliado al Centro de Obreros de Allen (Casiano Ruggieroni, italiano, 25 años, bracero). ${ }^{4} \mathrm{Al}$ año siguiente el periódico anarquista Brazo y Cerebro, editado en Bahía Blanca, dará cuenta de una huelga de hambre llevada a cabo por estos reclusos en protesta por los castigos recibidos, además el artículo resalta su injusta condena. ${ }^{5}$

A principios de 1930 -según un relevamiento policial- en la región valletana se registraba la actividad de los gremios ferroviarios (Río Colorado, Darwin), de Oficios Varios en Ing. Huergo y Cinco Saltos, la Sociedad de Empleados de Comercio también estaba en la zona. En las décadas del 20 y 30 los trabajadores empacadores de frutas protagonizaron huelgas -en plena cosecha- por reivindicaciones salariales y mejores condiciones de trabajo (Rafart y Mases, 2003: 41).

La presencia de grupos anarquistas activos puede testimoniarse el 1 de mayo de 1930 -pocos meses antes del golpe del 6 de setiembre-cuando la ciudad de Roca fue escenario de un acto recordatorio, si bien "no pudieron contar con la presencia de un delegado de la FORA por falta de dinero para costear su viaje", la crónica de lo acontecido publicada en La Protesta nos "permite acceder a los temas que concentraron la atención de los oradores: la desocupación y las críticas a los socialistas 'disfrazados de obrerismo', que privilegiaban la vía electoral' (Etchenique y Scandizzo, 2001: 4).

La presencia de numerosos trabajadores en la zona-muchos de ellos con experiencias de luchas laborales- constituyó una simiente fértil para la aparición de expresiones como el anarquismo, el comunismo y el socialismo, esta última con presencia electoral en algunas municipalidades, como Gral. Roca donde llegaron a presidir el Concejo Municipal a mediados del 20 (Rafart y Mases, 2003: 32). Esta actividad sindical y política que acabamos de reseñar, viabiliza contextualizar y explicar la detención a principios de 1931 de un grupo de personas acusadas de actividades anarquistas, quienes mayoritariamente residian en localidades del Alto Valle.

4. AHPRN. Sección Justicia Letrada, Exp. 172/1923.

5. Brazo y Cerebro, 10 de octubre de 1924. 


\section{El accionar represivo en marcha}

El gobierno de José Félix Uriburu se caracterizó "por la práctica de una represión extrema", instauró la ley marcial y restableció la pena de muerte, que había sido abolida por el Congreso en 1921. Son disueltos los sindicatos -sobre todo los conducidos por anarquistas y comunistas-, sus dirigentes detenidos y los extranjeros deportados (Rouquié, 1981: 223).

La tortura -en sus diversas variedades- fue el método por excelencia empleado en los interrogatorios; según Ricardo Rodríguez Molas el saldo de ese período, "entre la creación en 1931 de la sección Orden Político para reprimir las ideas sociales consideradas de avanzada y el año 1934", se contabilizó que por sus calabozos pasaron 10.000 personas, y de ellas 500 habian sido torturadas, según un memorial elevado a la Cámara de Diputados (1984: 59).

Río Negro, como el resto del país, no se sustrajo a la acción represiva, que se materializó en la detención de un grupo de personas acusadas de ácratas, concretada entre la última semana de enero y primera de febrero de 1931, en medio de uno de los momentos de mayor represión para el movimiento, coincidente con el fusilamiento de Di Giovanni y Scarfó. Accionar que se apoyaba en las facultades otorgadas al Poder Ejecutivo por la imposición del estado de sitio -declarado inmediatamente después de ocupar la presidencia José Félix Uriburu luego del golpe militar- por el cual se suspendieron todas las garantías respecto a los arrestos.

De acuerdo a las informaciones publicadas en los periódicos locales La Nueva Era y Río Negro ${ }^{6}$-enero y febrero de 1931-, dieciséis presos anarquistas fueron traslados a Viedma, algunos de ellos, luego, son conducidos a la Capital Federal, ${ }^{7}$ la mayoria procedia del Alto Valle, unos pocos del Medio Valle y sólo uno residía en Río Colorado. ${ }^{8}$

El periódico viedmense La Nueva Era -en un artículo transcripto luego por el Río Negro de Roca- se refería a los detenidos como "conocidas figuras peligrosas del anarquismo", a quienes se les había "incautado material de propaganda subversiva" y algunos de ellos "poseian libros de química y textos sobre materiales explosivos". Además, manifiesta que por disposición del Jefe de Policía se guarda "absoluta reserva y no

6. La Nueva Era, 5, 14 y 21 de febrero de 1931; Río Negro, 29 de enero y 12 de febrero de 1931.

7. AHPRN, 6 de marzo de 1931. Nota de la Jefatura de Policía solicitando pasajes a Buenos Aires para conducir ácratas detenidos.

8. AHPRN, Prontuarios Orden Social (en adelante, OS), números 4, 6, 9, 10, 11, 13, 14, 15, 16, 17, 18, 23, 25 у 26. 
se dan noticias oficiales de ninguna naturaleza". Según el mismo artículo, los apresamientos se habian podido concretar por declaraciones de Mariano Rubio, detenido con anterioridad -"en posesión de numerosos elementos de propaganda subversiva"-y trasladado a la Capital Federal a disposición del poder Ejecutivo Nacional. ${ }^{9}$

Luego de esta primera nota informativa, el tema tuvo poca difusión en la prensa local -sólo una comunicación de la cantidad de personas detenidas acusadas de ácratas o una breve noticia de la vuelta a Viedma del comisario que actuó en el procedimiento o dentro de un artículo crítico por el hacinamiento que soportaba la cárcel local. ${ }^{10} \mathrm{~A}$ pesar de su pronta desaparición de la crónica periodística, consideramos que los hechos debieron tener una repercusión importante en las comunidades de origen de los acusados -efecto también buscado en este tipo de medidas- ya que se trataba de poblaciones pequeñas, ${ }^{11}$ aunque parte de los habitantes vivía en la zona rural, los predios no eran muy extensos y, dadas las características de las tareas agrícolas, prevalecian las relaciones cara a cara, en donde todos se conocen. Además, también hay que tener en cuenta que involucró a personas afincadas en el medio, algunas con diez años de residencia. Esta enunciación queda en el campo de la conjetura, pues con las fuentes que disponemos no es posible su comprobación.

Los antecedentes de los detenidos están contenidos en los Prontuarios -iniciados en la fecha de su detención pero que continuaron activos, en su mayoria, durante toda la vida del prontuariado- originados en la Sección Orden Social de la Jefatura de Policía de Río Negro. La información reunida en ellos permitió dilucidar los procedimientos de detención y vigilancia puestos en acción por la policia, a partir de las comunicaciones entre las comisarias y la Jefatura. Al mismo tiempo, el análisis de las transcripciones de interrogatorios e informes de allanamientos posibilitó conocer las trayectorias de vida de los detenidos, sus relaciones y conexiones locales y externas. Encontramos que, en algunos casos, los titulares de estos prontuarios fueron detenidos y/o

9. La Nueva Era, 7 de febrero de 1931; Río Negro, 12 de febrero de 1931. Del detenido Mariano Rubio no se ha encontrado ninguna otra referencia, de acuerdo a las fuentes disponibles.

10. La Nueva Era, 7, 14 y 21 de febrero de 1931; Río Negro, 29 de enero y 12 de febrero de 1931.

11. Cipolletti contaba con 5.000 habitantes (de alli procedian 5 detenidos), Roca con 8.800 ( 3 detenidos), Cervantes con 1.230 (2 detenidos), Río Colorado con 7.800 (1 detenido) y Choele Choel con 3.050 (3 detenidos). Las cifras de población corresponden al 31 de diciembre de 1933 por apreciación de las comisarías de policía, según la Memoria de la Gobernación de Río Negro de 1933. 
interrogados -siempre por cuestiones politicas- en distintas ocasiones posteriores a 1931 .

El procedimiento empleado en los arrestos -reconstruido por testimonios documentales originados en detenciones posteriores-, ${ }^{12}$ se iniciaba -en los Territorios Nacionales- con una nota de solicitud expedida por la Jefatura de Policia del Territorio, luego elevada al Ministro del Interior a través del Gobernador, sin ninguna intervención judicial. La nota presentaba una sintesis de los antecedentes de la persona-con especial énfasis en detenciones anteriores-y explicitaba los motivos por los cuales era necesario efectuar el apresamiento. El detenido quedaba a disposición del Poder Ejecutivo y la privación de su libertad se prolongaba por el tiempo que juzgaran necesario las autoridades del Poder Ejecutivo, quienes a su vez también disponían de su libertad (Nazar, 2003).

Los prontuarios policiales, relevados en esta investigación, poco nos dicen sobre las causas que llevaron a detener a estas personas, pues solo una breve frase justifica el motivo del prontuario: "sindicado como anarquista”, “ácrata reconocido”. En general la acusación remite a que se los incriminaba como ácratas o que eran conocidos por profesar ideas anarquistas, si bien en algunos casos se aclara que no se les había comprobado su afiliación a ningún centro ni que mantenían correspondencia con personas de esas ideas, pero en la decisión de su apresamiento fueron determinantes los antecedentes relacionados con detenciones anteriores y las vinculaciones -ya sea de amistad o trabajocon otros conceptuados como anarquistas.

En cuanto a las disposiciones adoptadas con respecto al destino de los detenidos y de acuerdo a las fuentes disponibles, solo se pudo constatar que once de ellos, luego de una breve estancia en la cárcel de Viedma, fueron remitidos a la Cárcel de Devoto, donde permanecieron recluidos durante trece meses a disposición del Poder Ejecutivo Nacional. ${ }^{13}$ A los tres restantes, que estuvieron encarcelados por unos dias, se les dispone su libertad por falta de mérito, si bien se deja constancia que "se le establece vigilancia a efectos de comprobar si efectivamente hacen propaganda contra el gobierno provisional". ${ }^{14}$

12. AHPRN, Prontuarios OS No 36 al 47, todos iniciados en el año 1933, son mucho más completos.

13. Algunos de ellos van a sufrir detenciones por las mismas imputaciones en los años posteriores.

14. AHPRN, Prontuarios OS No 9, 10, 26. 


\section{Caracterización de los detenidos acusados de ácratas}

Referencias personales, residencia y trabajo

Los integrantes del grupo tenían entre 35 a 47 años de edad. En cuanto a su nacionalidad, solo uno es argentino, el resto son extranjeros: españoles (8), portugueses e italianos ( 2 y 2) y un chileno. Todos ellos con una residencia en el país entre 20 y 22 años y en Río Negro, en algunos casos, se extendía a los 10 años, si bien la mayoría registraba menos tiempo. En el momento de su detención estaban afincados en las localidades de Cipolletti, Cervantes, General Roca, Choele Choel y Río Colorado.

Su historia de vida es la historia de la mayor parte de los inmigrantes: la búsqueda de trabajo los obligó a recorrer el país, es así que la mayoría de ellos había pasado por distintos pueblos de las provincias de Buenos Aires y Santa Fe, de los territorios de La Pampa y Chubut, desempeñándose como peones en la construcción del Dique Contralmirante Cordero, el Canal de la Colonia Cipolletti, en las obras de cloacas en la Capital Federal, integrando las cuadrillas del Ferrocarril Sud o de YPF, jornalero en las cosechas de trigo, papa, fruta, trabajando en chacras, empacadoras de frutas. En tanto, los investigadores Etchenique y Scandizzo afirman que "el tránsito de militantes [anarquistas] entre Bahía Blanca y el Alto Valle fue continuo, algunos hombres llegaron de la ciudad puerto y se instalaron en el naciente territorio, otros optaron por un continuo peregrinaje entre el sur bonaerense y el norte rionegrino" (2001: 3).

Al momento de su detención hay quienes alternaban su trabajo en labores agrícolas con la pesca, en un caso se trataba de pobladores de una isla cercana a Cipolletti ${ }^{15}$ y en otro, de residentes en Choele Choel, mientras que el resto declararon ser jornaleros, dedicados a trabajos rurales e incluso se registra un tonelero y un maquinista de trilladora, estos últimos domiciliados en Roca. ${ }^{16}$ Sin conexión con la actividad agrícola tenemos un tipógrafo, un vendedor ambulante y un pintor, este último residente en Río Colorado. ${ }^{17}$

15. AHPRN, Prontuario OS N ${ }^{\circ} 11$, correspondiente a Antonio Vives, quien había enviado una carta al periódico anarquista La Antorcha en el año 1924 refiriéndose a los momentos críticos que atravesaban (Etchenique y Scandizzo, 2001: 2).

16. AHPRN, Prontuario OS No 11, 13, 14, 17.

17. AHPRN, Prontuario OS No 9, 16, 4. 
El historial policial

A partir de los datos consignados en las planillas "Procesos y Arrestos Sufridos" y "Motivo del prontuario y Otros Antecedentes" insertas en los prontuarios podemos responder a la pregunta: ¿qué los hacía peligrosos? En la mayoria de los casos eran sus detenciones anteriores, unos bajo la acusación de ácratas, otros por infracción a la ley social o por atentado a la autoridad (por ejemplo la participación en una huelga en el puerto de Bahía Blanca) ${ }^{18}$ o por repartir manifiestos anarquistas en la Capital Federal. ${ }^{19}$ También otro antecedente consignado como peligroso fue la pertenencia a la FORA "mientras trabajó de ladrillero en Bahía Blanca". ${ }^{20}$

El intercambio de información de las policías de las distintas provincias, territorios y Capital Federal jugó un papel fundamental en el registro de antecedentes y sentará las bases de la denominada "comunidad informativa", constituyéndose en una decisiva herramienta del engranaje represivo. Por ejemplo en uno de los casos, un informe de la policía de la provincia de Buenos Aires que lo señalaba como anarquista peligroso bastó para ordenar su detención, a pesar de que el comisario local lo consideraba una persona apreciada en la comunidad. ${ }^{21}$

Los prontuarios abiertos en 1931 a estos detenidos, mantuvieron una vida activa durante un largo tiempo, muchos de estos movimientos obedecen a requerimientos de antecedentes por parte de diversos organismos, como los demandados por el Comando Comunicaciones de la $6^{\circ}$ División del Ejército con asiento en Neuquén y por la División Informaciones Políticas de la Presidencia de la Nación, ambos en 1949, que comprendía a la mayoría de estos detenidos. ${ }^{22}$ En una época más próxima -año 1962- se elevan antecedentes de uno de estos presos, a requerimiento de la Subsecretaria de Gobierno de la Provincia de Río Negro. ${ }^{23}$

La actualización de los Prontuarios se formalizaba en informes que elaboraban los comisarios de las localidades rionegrinas particularmente la Comisaría de Cipolletti se mostró muy diligente y minuciosa pues, entre 1937 y 1947, envió numerosos reportes de personas que regis-

18. AHPRN, Prontuario OS $N^{\circ} 13$.

19. AHPRN, Prontuario OS $\mathrm{N}^{\circ} 15$.

20. AHPRN, Prontuario OS $\mathrm{N}^{\circ} 17$.

21. AHPRN, Prontuario OS $\mathrm{N}^{\circ} 4$.

22. AHPRN, Prontuarios OS $N^{\circ} 11,13,14$.

23. AHPRN, Prontuarios OS N 13. 
traban antecedentes de "orden social" residentes en la localidad, todos ellos integrantes del grupo de acusados de ácratas de 1931. ${ }^{24}$

\section{Las trayectorias personales: vidas militantes}

A través de los datos que se fueron acopiando en los Prontuarios, se pudo reconstruir -en parte- la vida de algunos militantes detenidos en 1931, tanto su historia anterior como posterior a esa fecha. Esta fuente tiene un gran valor porque puede dar luz sobre personas y grupos -todos trabajadores- de los que hay pocos testimonios que den cuenta de su existencia, luchas e ideales. No obstante, este fondo documental por su finalidad, por las formas de su producción y procedencia -interrogatorios sin garantías constitucionales, violación de correspondencia, allanamientos, delaciones, persecuciones- debe ser sometido a riguroso análisis y crítica.

En este trabajo presentamos la reconstrucción de la trayectoria de vida de dos de ellos, esta elección se vincula con la magnitud del contenido de sus legajos, que en estos casos es considerable pues se fueron actualizando e incrementando a través de los años, ya sea con informes policiales surgidos de una vigilancia permanente o porque contienen copia de sumarios y transcripción de interrogatorios efectuados durante las detenciones sufridas a lo largo de su vida y, también, porque incluyen la descripción del material incautado durante allanamientos: libros, folletos, cartas, fotografias y documentos personales.

Juan Bautista Mattalia Perano o José Perano. En 1931, este italiano tenía 47 años cuando fue arrestado en la localidad rionegrina de Río Colorado, acusado de ácrata. En esta decisión gravitaron sus detenciones anteriores: en 1918 y 1920 por infracción a la Ley Social y en 1919 por anarquista, todos en Bahía Blanca, su residencia desde 1908. Ciudad donde integró el grupo editor de Brazo y Cerebro, además de publicar en otro periódico anarquista local como Mar y Tierra y también en la prensa libertaria de Buenos Aires, sobre todo en El Trabajo y en Bandera Proletaria. Fue una etapa de su vida de gran actividad pero también de "persecuciones y cárceles", esta circunstancia lo motivó a "llamarse simplemente José Perano", "manera habitual entonces de camuflar la identidad, cambiándose el nombre y el lugar de residencia". (Quesada, 1975: 76).

En Bahía Blanca "participó en el Sindicato de Pintores, dio conferencias, colaboró en periódicos, redactó manifiestos y declaraciones", además de ser un protagonista destacado de la cultura, en tanto actor 
y director de un cuadro de aficionados que "representaban obras de tesis", asî llamadas entonces, representadas no sólo en Bahía Blanca sino también en poblaciones de la zona (Quesada, 1975: 76).

Además, las localidades de Punta Alta e Ingeniero White lo contaron como vecino; en esta última, durante una corta temporada, instaló una librería destinada a la difusión de la prensa y la bibliografia anarquista. Esto explica por qué en la planilla prontuarial, confeccionada por la policía de la provincia de Buenos Aires en 1918, aparece como comerciante. Esta policia lo registra como "un anarquista peligroso, fabricante de bombas explosivas y dinamita". ${ }^{25}$

Si bien se desempeñó como pintor y electricista durante buena parte de su vida, también "fue jornalero, trabajó en las cosechas. Independizado antes de cumplir 20 años, realizó un extenso peregrinaje de norte a sur" (Quesada, 1975: 75).

Antes de radicarse en Río Negro, en setiembre de 1925 viajó a Roca -en una gira coordinada por la organización local Progreso y Culturapara participar en distintos actos, uno realizado en la plaza del pueblo y dos en la confitería "Las familias", donde se proyectó el film Fecundidad, basado en una obra de Emilio Zola (Etchenique y Scandizzo, 2001: 3-4).

Afincado en Río Negro, fue encarcelado en Río Colorado -año 1931por antecedentes anarquistas, si bien al año siguiente la policía de Río Negro informó que "no se dedica a actividades propias de sus ideas", "no existen constancias concretas de actos violentos que haya ejercido o participado", ocupándose desde hace varios años en trabajos de pintura, en la jurisdicción de la Comisaría de Río Colorado, "donde goza de general simpatía siendo muy apreciado aún por las personas que representan el capital de aquel punto". Por esa época había constituido su familia -en concubinato- y era padre de cuatro hijos. ${ }^{26}$

Contribuyendo a la eficiencia en el intercambio de información entre policías, la de Bahía Blanca le comunica a la territoriana que en un allanamiento realizado a la Secretaría General de la Federación Anarcocomunista de esa ciudad en 1937, se incautó un listado de afiliados, donde figuraba José Perano como un activo militante.

La última constancia que presenta su prontuario en la policía de Río Negro es una nota de la comisaría de Río Colorado -fechada en 1938notificándole a la de Cinco Saltos que este sujeto "catalogado como ácrata" ha trasladado su residencia a esa ciudad. En tanto, Fernando Quesada consigna que sus últimos años transcurrieron en Mar del Plata, donde fallece a los 75 años (1975).

25. AHPRN, Prontuario OS $\mathrm{N}^{\circ} 4$.

26. AHPRN, Prontuario OS No 4. 
Juan Hernández Lázaro. Español nacido en 1896, llegó al país en 1912, desempeñándose como jornalero en trabajos diversos y luego como agricultor en su propia chacra. Su prontuario se inicia en 1931 -con motivo de su apresamiento- cuando tenía 35 años y el último registro es de 1962, con 66 años, es decir que contiene gran parte de su vida. ${ }^{27}$

Registra numerosas detenciones, una de ellas en 1924 durante 10 dias, acusado de atentar contra la autoridad por participar en una huelga de dos semanas en el puerto comercial de Bahía Blanca, donde trabajaba como bolsero en la casa Dreyfus. Otra en 1931, en Cervantes -localidad rionegrina- acusado de actividades anarquistas y puesto a disposición del Poder Ejecutivo Nacional, es trasladado a la cárcel de Devoto, donde permaneció un año.

En 1939, su afán se volcó a la formación de una asociación de seguidores de las ideas anarquistas, así surgió ese año la Agrupación Cultural de Río Negro, que lo tuvo como activo participante en su cargo de secretario. En su declaración -durante el interrogatorio a que fue sometido en su detención de 1943- manifiesta que los objetivos proyectados por la Agrupación se relacionaban con la intención de asistir a los refugiados españoles y difundir las ideas anarquistas. Además, nos informamos -por la misma vía- que la primera reunión de la Agrupación tuvo lugar en Ing. Huergo, donde se realizó una función de cine para recaudar fondos destinados a las victimas de la guerra española, mientras que los encuentros posteriores se realizaron en su chacra, con la participación entre 10 y 12 personas. La circulación de 500 volantes -impresos en los periódicos La Obra y La Protesta- que daban a conocer las intenciones de esta Agrupación, permitió difundir su creación entre los trabajadores ambulantes y los chacareros de la zona, si bien su existencia sólo se prolongó por un año. En tanto, los fondos recolectados se destinaron al afianzamiento de las ideas anarquistas, en especial para la compra de libros y folletos de propaganda, para ser distribuidos en las épocas de cosechas por parte de Martínez Carricondo (José Maria), capataz de un galpón de empaque.

Al respecto, el comisario, encargado del sumario, en su informe considera que la "entidad se desenvolvía ocultamente y creada con la finalidad de difundir esa clase de propaganda disolvente, conseguir adeptos para la ideología y reunir fondos que destinaban en ayuda de presos sociales y refugiados políticos extranjeros". ${ }^{28}$

En la década del 40 está afincado en una chacra de 12,50 ha de su propiedad (en sociedad posee otra de la misma superficie) en la jurisdicción de General Roca, con vivienda, animales (5 vacas, 7 yeguarizos),

27. AHPRN, Prontuario OS N ${ }^{\circ} 13$.

28. AHPRN, Prontuario OS No 13. 
implementos agrícolas ( 2 rastrones, cortadora de pasto, arado de dos discos y de mancera), varias herramientas de labranza e instrumentos diversos. Su esposa, también española, y dos hijos de crianza de 15 y 8 años, constituían su familia.

Por esos años es detenido dos veces, una en 1943, durante cinco meses y otra, en 1944, permaneciendo 8 meses en la cárcel, en ambas acusado de actividades anarco-comunistas. En la primera se le atribuye la distribución de folletos y de los periódicos anarquistas La Obra y La Protesta. En esas actuaciones, el comisario instructor del sumario dejó asentada sus apreciaciones en cuanto al peligro que suponía la distribución de toda esa prensa que "sustentaba preceptos ideológicos anarquista y preconiza la implantación de esa doctrina" entre los trabajadores del campo y en especial los ambulantes, que llegaban a la zona para la recolección e industrialización de la fruta, "actividad que presupone una campaña de agitación propensa a originar huelgas o conflictos obreros que ocasionarian sensibles perjuicios de orden económico y comercial con la consiguiente perturbación del orden público". ${ }^{29}$

Cuando el inquisidor policial -respaldado en fotografias, cartas y documentos personales incautados durante los allanamientos- orienta su interrogatorio hacia los lazos de amistad, los lugares de encuentro, los compañeros de trabajo, esto nos permitió reconstruir su círculo de relaciones. Así nos informamos que mantenía correspondencia con José Berenguer, director del periódico La Protesta, con Donato Rizzo domiciliado en Buenos Aires, compañero en prisión de Devoto y con Martín Gómez, simpatizante anarquista local. Además, reconoce que mantiene amistad con quienes compartió el cautiverio de Devoto en 1931-residentes en Cipolletti- , y que, en sus actividades ideológicas, su mayor vinculación es con Martínez Carricondo, desde hace unos 7 u 8 años.

A partir de la reseña detallada de los folletos, libros y periódicos que le son confiscados en 1943 -registrados en los informes de allanamientos y aludidos durante los interrogatorios-, podemos afirmar que su biblioteca era muy notable para un trabajador. Se advierte que, a 12 años de su primera detención en Río Negro, había reforzado su orientación político-ideológica a partir de la lectura de autores anarquistas como Max Nettlau (Errico Malatesta, la vida de un anarquista; Eliseo Reclus, la vida de un sabio justo y rebelde), Rudolf Rocker (Johann Most. La vida de un rebelde), Manuel González Prada (La anarquía, las ideas, los hechos, Propaganda y ataque), Pedro Kropotkin (Memorias de un revolucionario, La anarquía, su filosofia, su ideal), Ettore Zoccoli (La anarquía los agitadores, La anarquía. Apreciaciones éticas). 
Además, incluía una presencia importante de obras referidas a la República Española y a la guerra civil en España, como Madrid rojo y negro de Eduardo Guzmán, Doy fe de Antonio Ruiz Vilaplana (publicación del Comité Defensa República Española), Cómo se enfrentó al fascismo en toda España de Federica Montsenny, España levanta el puño de Pablo Suero y Largo Caballero denuncia la traición del partido comunista español. Complementándose con textos antifascistas (Anna Siemsen, El Imperio Germano peligro de Europa), estudios sobre el origen de la sociedad y la religión (Conde de Volney, Las ruinas de Palmira), escritos referidos al marxismo (V. Tcherkesol, Páginas de historia socialista. Confesión de Karl Kautzky) y novelas sociales (Octavio Rivas Rooney, Extranjeros en su tierra. Hombres y paisajes del norte argentino).

Al respecto, manifiesta que todos los libros y folletos secuestrados son "de su propiedad y los adquirió para su lectura" y que a veces se hacian colectas voluntarias para solventar el costo de los periódicos, importe que era girado a la dirección de La Protesta. Ante la pregunta sobre la posesión del carnet de la Guilda de Amigos del Libro, ${ }^{30}$ aclara que "esa sociedad ya no existe más pero cuando funcionaba con solo abonar un peso mensual se le enviaba un libro que esa sociedad publicase cualquiera sea su precio". El informe policial resalta el peligro que constituia "vender o simplemente facilitar a trabajadores de escasa capacidad intelectual textos de lectura de avanzado saber doctrinario que esta policía secuestró".

En 1944, la Sección Orden Social -luego de "practicada una minuciosa compulsa de los antecedentes que obran en esta División sobre la personalidad, condiciones de trabajo, volumen social, económico y moral, concepto y demás datos"-informa que Hernández Lázaro es detenido en posesión de "abundante material de lectura de tal ideologia [anarquista]", "pero su actividad en ese sentido era relativa, sin ascendiente social ni suficiente preparación, vive del trabajo de la fruticultura", "la situación económica de éstos [familia] es precaria", "trátase de un hombre rústico y tranquilo no considerándose peligroso".

El último registro de su prontuario es una providencia -fechada el 3 de agosto de 1962- originada en la División Investigaciones de la Policía destinada al Subsecretario de Gobierno del Territorio de Río Negro, en ella informa que eleva un expediente con los antecedentes de Hernández Lázaro que constan en su legajo, a partir de ello no tenemos más información sobre su vida.

30. Asociación de amantes del libro dirigida por Abad de Santillán que distribuía literatura anarquista. 


\section{A modo de conclusión}

La represión política y social llevada a cabo durante las décadas del 30 y 40 -con todos sus dispositivos y prácticas intensificados por el régimen militar - se extendió por todo el país y Río Negro no se sustrajo a esa situación.

La detención y posterior confinamiento de un grupo de personas en 1931-bajo la imputación de anarquistas- se constituye, según las fuentes que se disponen y la historiografia conocida, en la primera manifestación de represión política en territorio rionegrino. Si bien hubo hechos anteriores que se pueden incluir dentro de la categoría de represión política, éstos fueron casos aislados, encubiertos bajo la acusación de delitos como asociación ilícita o atentado a la autoridad.

El caso estudiado tuvo epicentro en el Alto Valle, región que presentaba una concentración importante de trabajadores -muchos de ellos con antecedentes de participación en luchas gremiales en otras provincias- y una incipiente organización sindical en distintas ramas y oficios. Simultáneamente con estos arrestos, se organizó en la Policía de Río Negro la Sección Orden Social encargada de la instrucción de los Prontuarios, instrumento fundamental en el apoyo de las actividades de control, persecución y represión.

Para quienes concebian y ejecutaban estas medidas represivas, el grupo de anarquistas detenidos reunía las características que los identificaba como "agitadores", "disolventes", es decir peligrosos, avalando su represión, convirtiéndolos en "presos sociales", ya que mayoritariamente eran inmigrantes, con detenciones anteriores vinculadas a la participación en huelgas o por actuación gremial; su trajinar para ganarse el sustento los había llevado a tener contacto con otros trabajadores de diversos puntos del país; su gusto por la lectura los hacía poseedores de materiales de contenido político contrario al orden social, que en algunos casos facilitaban para su circulación entre seguidores, conocidos y trabajadores; se destacaban por su militancia, por impulsar organizaciones de difusión del "ideal que profesaban" y mantenían una estrecha relación con allegados a sus ideas y compañeros de cárcel.

Las formas y alcances de la represión política es un tema poco investigado por la historiografia de las jurisdicciones que hasta mediados de la década del 50 conformaron los Territorios Nacionales. Con esta investigación se pretendió realizar un aporte a la temática, pero consideramos que la misma requiere ser profundizada a los efectos de rastrear su genealogía y comprender los cambios y continuidades, que solo es posible visualizarlos en un lapso temporal amplio. Además, para superar los estudios de casos locales, debemos proponernos análisis 
comparativos entre los distintos Territorios Nacionales y, a su vez, con el resto de las Provincias, para descubrir similitudes y diferencias.

Las nuevas investigaciones sobre el ejercicio de la violencia por parte del Estado -de larga y nefasta supervivencia- posibilitarán dar cuenta de su alcance y efectos en la vida de las personas, de los grupos, todos ellos trabajadores, militantes politicos, activistas gremiales pero también -muy especialmente- para conocer sus ideales, sus resistencias, sus luchas.

\section{Bibliografia}

Anapios, Luciana (2007), "Compañeros, adversarios y enemigos. Conflictos internos en el anarquismo argentino en la década del 20", Entrepasados, 32.

Benyo, Javier (2005), La Alianza Obrera Spartacus. Anarquismo, vanguardia obrera e institucionalización del movimiento sindical en la década de 1930, Buenos Aires: Libros de Anarres.

Bracamonte, Lucía (2006), "Anarquismo y cuestión femenina. Una visión sobre lo público y lo privado en la prensa de Bahía Blanca a principios del siglo XX", e-l@tina, Revista electrónica de estudios latinoamericanos, $\mathrm{N}^{\circ} 16$, julio-septiembre, pp. 5-24, www.iigg.fsoc.uba.ar/elatina.htm.

Ceruso, Diego (2011), "El trabajo sindical de base del anarquismo argentino: la FACA y la Alianza Obrera Spartacus", A Contracorriente, vol. 8, $\mathrm{N}^{\circ} 3$, primavera.

Elbert, Carlos (1998), Manual básico de criminología, Buenos Aires: Eudeba.

Etchenique, Jorge y Hernán Scandizzo (2001), “Apuntes para una historia del movimiento anarquista en el Alto Valle del Río Negro, 1920-1930", ponencia presentada en el IV Congreso de Historia Social y Politica de la Patagonia Argentino-Chilena, Trevelin, 14 al 16 de Noviembre. Actas publicadas en CD.

Ferrás, Graciela (2003), "La figura del extranjero en el proyecto políticocultural de las élites", en S. Villavicencio (ed.), Los contornos de la ciudadanía. Nacionales y extranjeros en la Argentina del Centenario, Buenos Aires: Eudeba.

Flier, Patricia (2006), "El archivo de la DIPBA: un hallazgo clave para una historia de los imaginarios represivos en Argentina”, Imago Americae, Revista de Estudios del Imaginario, año I, $\mathrm{N}^{\circ} 1$, Centro Extremeño de Estudios y Cooperación con Iberoamérica, Universidad de Guadalajara, Universidad de Florencia y Universidad Nacional de La Plata, pp. 226227.

Iñigo Carrera, Nicolás (2009), "La clase obrera argentina a comienzos de los 30. Sistema institucional, partidos y clase: apuntes para una lectura crítica", Jornadas "A 40 años del Cordobazo: ciento treinta años 
de historia de las luchas de la clase obrera en Argentina, 1878-2008", Córdoba, 27 y 28 de mayo.

Iñigo Carrera, Nicolás (2000), "La Alianza Obrera Spartacus”, PIMSA, Buenos Aires, $\mathrm{N}^{\circ} 4$, año IV.

Iuorno, Graciela, Glenda Miralles y Karim Nasser (2007), “Actores y espacio público en la etapa territorial rionegrina. El Departamento General Roca y su integración desigual", en Ruffini y Masera (coords.), Horizontes en perspectiva. Contribuciones para la historia de Rio Negro. 1884-1955.

Lanzillotta, María E. y María de los A. Folco (2007), "Ese fragmento del mundo... Memoria e identidad en la prensa libertaria del Territorio Nacional de La Pampa (1922-1930)", ponencia presentada en Jornadas "Mundos posibles, mundos alternativos. (Re) Creando las tradiciones utópicas de América Latina", Universidad Nacional de Educación a Distancia (España) e Instituto de Desarrollo Humano de la Universidad Nacional de Gral. Sarmiento (Argentina), Los Polvorines, 15-16 noviembre.

Martínez Mazzola, Ricardo (2003), “¿Cuestión social o cuestión nacional? Los debates en torno al naciente movimiento obrero", en S. Villavicencio (ed.), Los contornos de la ciudadanía. Nacionales y extranjeros en la Argentina del Centenario, Buenos Aires: Eudeba.

Migueláñez Martínez, María (2010), Anarquistas en red. Una historia social y cultural del movimiento libertario continental (1920-1930), $9^{\circ}$ Encontro Internacional da ANPHLAC, Universidade Federal de Goiás, 26 a 29 de julio.

Migueláñez Martínez, María (2010), “1910 y el declive del anarquismo argentino: ¿hito histórico o hito historiográfico?”, XIV Encuentro de Latinoamericanistas Españoles.

Nazar, M. (2003), La accesibilidad documental y sus limitaciones legales: los documentos secretos en la Argentina, ponencia presentada en el V Congreso de Archivologia del Mercosur y XII Jornadas de Archiveros de la Argentina, Huerta Grande, Córdoba, agosto.

Nieto, Agustín (2010), "Notas críticas en torno al sentido común historiográfico sobre "el anarquismo argentino"”, A Contracorriente, vol. $7, \mathrm{~N}^{\circ} 3$, primavera, 219-248.

Pegoraro, Juan (2003), "La violencia, el orden social y el control social penal", Revista Brasileira de Ciencias Criminais, $\mathrm{N}^{\circ} 45$, octubre-diciembre.

Pérez, Pablo (2002), "El movimiento anarquista y los orígenes de la federación libertaria argentina", en P. Pérez (coord.), Catálogo de publicaciones politicas sociales y culturales anarquistas, 1890-1945. Consultado el 5 de marzo de 2007 en el sitio http:/ /www.nodo50.org/bpji/fla.doc (arch Cop/imp).

Pérez, Pablo, Juan Heredia y Hernán Villasenin (2005), El trabajo cultural del anarquismo, Buenos Aires: La Biblioteca - Archivo de Estudios Libertarios de Buenos Aires.

Quesada, Fernando (1975), "Tres vidas libertarias", Todo es Historia, No 94, Buenos Aires. 
Rafart, Gabriel y Enrique Mases (2003), "Economía, sociedad y política en los tiempos preperonistas", en G. Rafart y E. Mases (dirs.), El peronismo desde los territorios a la Nación. Su historia en Neuquén y Río Negro (1943-1958), Neuquén: EDUCO.

Rodríguez Molas, Ricardo (1984), Historia de la tortura y el orden represivo en la Argentina, Buenos Aires: Eudeba.

Roucco, Laura (2009), Sindicalismo anarquista y mujeres obreras del pescado. Dos paradigmas en el SOIP de Mar del Plata en 1942, ponencia presentada en XII Jornadas Interescuelas de Departamentos de Historia, Bariloche, 26 a 31 octubre.

Rouquié, Alain (1981), "Dictadores, militares y legitimidad en América Latina", en Crítica y Utopia Latinoamericana de Ciencias Sociales, Dictaduras $y$ dictadores, $\mathrm{N}^{\circ} 5$, Buenos Aires, Septiembre.

Ruffini, Martha (2007), La pervivencia de la república posible en los territorios nacionales: poder y ciudadanía en Rio Negro, Bernal: Universidad Nacional de Quilmes.

Suriano, Juan (2000), "El anarquismo", en Mirta Z. Lobato (dir.), Nueva historia argentina, vol. 5: El progreso, la modernización y sus limites (1880-1916), Buenos Aires: Sudamericana.

Vapnarsky, César (1983), Pueblos del norte de la Patagonia, 1779-1957, General Roca: De la Patagonia.

Zimmermann, Eduardo (1995), Los liberales reformistas. La cuestión social en la Argentina, 1890-1916, Buenos Aires: Sudamericana.

\section{Repositorios y fuentes}

Archivo Histórico Provincia de Río Negro (AHPRN), Sección Justicia Letrada, Sección Jefatura de Policía, Notas, Sumarios, Prontuarios de Orden Social.

Memoria de la Gobernación del Territorio de Río Negro de 1933, Gobernador Ing. Adalberto T. Pagano, Viedma, 1934.

\section{Periódicos}

Brazo y Cerebro (Bahía Blanca, 1924)

La Nueva Era (Viedma, 1930-1931)

Río Negro (Gral. Roca, 1930-1931)

$$
* * *
$$

Resumen: El quiebre del orden institucional en 1930, constituyó una etapa de recrudecimiento de las detenciones, deportaciones y fusilamientos para las organizaciones obreras, anarquistas y comunistas. Al estudiar esta represión en el Territorio de Río Negro, nos centramos en la detención de un grupo de personas bajo la acusación de ácratas, llevada a cabo en 1931. Nuestro propósito es 
presentar una caracterización de los detenidos, tratando de delinear trayectorias de vida de alguno de ellos. Además, descubrir evidencias que orienten a afirmar que los arrestados - por su nacionalidad, ocupación, antecedentes laborales, políticos y gremiales- participaban de la imagen del enemigo interno construida por las elites gobernantes. Dentro de las fuentes trabajadas, los Prontuarios Policiales de Orden Social se constituyeron en fundamentales.

Palabras clave: Río Negro - Represión - Anarquistas

Abstract: The breakdown of the institutional order in 1930, constituted a period of upsurge in arrests, deportations and executions for the workers' organizations, particularly anarchists and communists. In studying this repression in the National Territory of Rio Negro, we focus on the arrest of a group of people under the accusation of acratas, carried out in 1931. Our purpose is to present a characterization of the detainees, trying to delineate life histories of some of them. Also, discover evidence that orient to assert that those arrested - by their nationality, occupation, employment history, political and syndical - participated of the internal enemy image built by the ruling elites. Inside sources worked, the Prontuarios Policiales of Social Order was constituted in fundamental.

Keywords: Río Negro - Repression - Anarchists

Recepción: 30 de septiembre de 2012. Aprobación: 6 de diciembre de 2012 